\title{
CROMATOGRAFIA DE AFINIDADE COM ÍON CU²+: ELIMINAÇÃO DE FALSO-POSITIVOS NA DETECÇÃO DE ENTEROTOXINA ESTAFILOCÓCICA
}

\author{
CLAUDIA VALÉRIA NERVINO * \\ CLAUDIA ROSA MORENO ** \\ MARCIA KAMOGAE ** \\ TEREZA CRISTINA ROCHA MOREIRA DE OLIVEIRA *** \\ ELISA YOKO HIROOKA ***
}

\begin{abstract}
Avaliou-se a aplicação da cromatografia de afinidade com íon $\mathrm{Cu}^{2+}$ para minimizar a interferência de componentes alimentares na detecção de enterotoxinas estafilocócicas mediante imunoensaio, baseado em aglutinação de látex (RPLA). Os ensaios preliminares com "chantilly" contaminado com $25 \mathrm{ng}$ de enterotoxina estafilocócica A (EEA) indicaram que a cromatografia de afinidade com íon $\mathrm{Cu}^{2+}$ eliminou interferentes que causavam reação falso-positiva em RPLA. A eficiência do procedimento de limpeza foi testada em 15 extratos alimentares (de surtos e/ou com alta contagem estafilocócica), compreendendo vários tipos de alimentos comumente consumidos no Brasil. Onze extratos alimentares apresentaram um pico único de eluição com perfis semelhantes e as frações testadas por RPLA demonstraram EEA (4 alimentos), EEB (1), EEA + EEB (3), EEA + EED (2) e $E E A+E E B+E E D(1)$. Os problemas de reações inespecíficas com "kit" RPLA em 2 extratos de bolos recheados foram eliminados, indicando que a adoção desta operação evitaria a reação falso-positiva.
\end{abstract}

PALAVRAS-CHAVE: CROMATOGRAFIA; ENTEROTOXINA; ION CU²+; ALIMENTOSCONTAMINAÇÃO.

* Mestre em Ciências de Alimentos, Prefeitura Municipal de Curitiba, Secretaria Municipal da Saúde, Centro de Saúde Ambiental, Curitiba, PR. (e-mail: nervino@terra.com.br).

** Pós-Graduandos em Ciência de Alimentos, Universidade Estadual de Londrina (UEL), Londrina, PR.

*** Docentes do Programa de Pós-Graduação em Ciência de Alimentos, Departamento de Tecnologia de Alimentos e Medicamentos, Centro de Ciências Agrárias (CCA), UEL, Londrina, PR. (e-mail: hirooka@uel.br). 


\section{INTRODUÇÃO}

Testes rápidos para a detecção de antígenos microbianos vêm sendo amplamente difundidos, em função da necessidade de agilidade no controle de qualidade. As vantagens de simplicidade e sensibilidade apresentadas pelos imunoensaios tornaram tais métodos os mais utilizados para detecção de enterotoxinas estafilocócicas (IGARASHI et al., 1986; CHANG \& HUANG, 1994; CARMO, 1996). Não obstante, a eficiência na detecção em nível de nanogramas pode acarretar certas limitações, sendo as reações falso-positivas as principais devido à interferência de componentes alimentares. Assim, as metodologias desenvolvidas estão expostas ao risco de reações inespecíficas, oriundas de matrizes inerentes a cada tipo de alimento, antígenos microbianos e metabólitos extracelulares (OLIVEIRA, 1994; PARK \& WARBURTON, 1996; KAWANO et al., 2000).

Nos "kits" comerciais de aglutinação de látex reversa e passiva (RPLA), as reações falso-positivas decorrem da reatividade inespecífica com componentes lipídicos, protéicos e açúcares presentes em alimentos como maionese, queijo e creme (PARK \& SZABO, 1986; WIENEKE \& GILBERT, 1987; ROSE et al., 1989; SOUZA-CUNHA, 1992; KAMOGAE, 1994). Estes interferentes devem ser eliminados durante o processo de extração que consiste na transferência de enterotoxinas presentes no alimento para a fase aquosa (MORISSETE et al., 1991). A adequada limpeza dos extratos alimentares constitui etapa imprescindível na eliminação de reações falsopositivas em imunoensaios, principalmente no RPLA, que apresenta metodologia de execução sem etapas de lavagem e, portanto, mais simples do que o enzima imunoensaio (ELISA).

O tratamento térmico do extrato, absorção com soro de coelho, diluição e cromatografia de afinidade com íon $\mathrm{Cu}^{2+}$ foram apontados entre os procedimentos capazes de minimizar e/ou eliminar reações inespecíficas (DICKIE \& AKHTAR, 1989; PARK \& WARBURTON, 1996). A cromatografia de afinidade com íons imobilizados na sepharose constitui uma variante da cromatografia de adsorsão, descrita primeiramente por PORATH et al. (1975) para a purificação de proteínas. O fundamento desta cromatografia baseia-se na formação de um complexo entre os íons imobilizados e os resíduos de histidina, cisteína e triptofano. Estes aminoácidos ligam-se ao íon metálico em pH 6,0-8,0 e são eluídos diminuindo-se o pH e a força iônica (LÖNNERDAL \& KEEN, 1982). Na cromatografia de afinidade "cooper chelate sepharose", a substância ligante $\mathrm{Cu}^{2+}$, imobilizada na matriz de sepharose, retém seletivamente a enterotoxina estafilocócica, 
que é eluída com imidazol, aliando-se assim as vantagens da purificação parcial e a concentração na solução de enterotoxina (DICKIE \& AKHTAR, 1989; PARK et al., 1993). A literatura menciona avanços na metodologia baseados no anticorpo imobilizado na superfície de sensores, capazes de acoplar a função de concentrar/detectar (NEDELKOV et al., 2000), assim como a cromatografia "countercurrent", que utilizando partição contínua de soluto entre duas fases líquidas descarta o suporte sólido (RASOOLY \& ITO, 1998; 1999). Todavia, a utilização destes métodos na rotina laboratorial ainda está longe da realidade brasileira.

Considerando os problemas emergentes de interferência na detecção direta de enterotoxinas estafilocócicas pelo RPLA, durante a análise de alimentos, avaliou-se a aplicabilidade da cromatografia de afinidade com íon $\mathrm{Cu}^{2+}$ nos produtos comumente consumidos pela população brasileira.

\section{MATERIAL E MÉTODOS}

\subsection{TIPOS DE ALIMENTOS}

A interferência da matriz alimentar no ensaio de RPLA foi analisada empregando-se "chantilly" comercial, artificialmente contaminado com enterotoxina estafilocócica A (EEA), 99\% de pureza, fornecida pelo Dr. Merlin S. Bergdoll, Food Research Institute, EUA. Com esta finalidade, $50 \mathrm{~g}$ de "chantilly" em duplicata foram contaminados com solução de tampão fosfato $0,05 \mathrm{M}, \mathrm{pH} \mathrm{7,2,} \mathrm{com} \mathrm{0,15} \mathrm{M} \mathrm{de} \mathrm{NaCl}$ (PBS) contendo $1,25 \mathrm{mg}$ de EEA, obtendo-se concentração final de $25 \mathrm{ng}$ de toxina/g. Paralelamente, enterotoxinas estafilocócicas também foram analisadas em 15 alimentos cedidos pelo Laboratório de Apoio Animal (LAPA/PR) e pelo Laboratório Central do Estado do Paraná (LACEN), sendo 9 implicados em surtos de intoxicação alimentar. As amostras apresentavam contagem

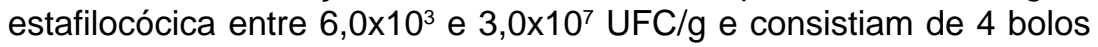
recheados, 4 queijos, maionese, lingüiça, mortadela, carne moída, costela defumada, frango cru e panqueca de carne.

\subsection{EXTRAÇÃO DE ENTEROTOXINAS ESTAFILOCÓCICAS}

Os extratos alimentares foram obtidos homogeneizando-se volumes iguais dos alimentos com água destilada (50 g de "chantilly" + $50 \mathrm{~mL}$ de água ou $100 \mathrm{~g}$ de alimento $+100 \mathrm{~mL}$ de água), durante $1 \mathrm{~min}$ em liquidificador. $\mathrm{O}$ $\mathrm{pH}$ foi ajustado para 4,5 com HCl 6,0 N e após centrifugação a $15.000 \mathrm{~g}$ 
durante 20 min, o sobrenadante obtido foi ajustado para pH 7,2 a 7,4 com $\mathrm{NaOH} 5 \mathrm{~N}$.

\subsection{CROMATOGRAFIA DE AFINIDADE COM ÍON Cu²+}

Os extratos alimentares (chantilly e alimentos contaminados com estafilococos enterotoxigênicos) foram aplicados em coluna de afinidade " $\mathrm{Cu}^{2+}$ chelate sepharose", seguindo-se a metodologia descrita por DICKIE \& AKHTAR (1989).

Para acoplar o íon $\mathrm{Cu}^{2+}$, o gel ativado constituído de $5 \mathrm{~mL}$ de "epoxy activated-sepharose" $6 \mathrm{~B}$ (Sigma) foi lavado com $100 \mathrm{~mL}$ de $\mathrm{H}_{2} \mathrm{O}$ destilada e adicionado de $\mathrm{CuSO}_{4} \cdot 5 \mathrm{H}_{2} \mathrm{O} \cdot 0,5 \%(\mathrm{p} / \mathrm{v})$. Considerando-se que a proporção de gel ativado seja de 5 a $8 \mathrm{~mL}$ para 50 a $100 \mathrm{~mL}$, respectivamente de extrato, usou-se para a análise $5 \mathrm{~mL}$ do gel para $50 \mathrm{~mL}$ do extrato alimentar. A seguir, ajustou-se o pH da mistura para 7,4, a qual foi submetida à agitação (180 rpm por 1 hora, a temperatura ambiente em incubadora Superhom).

O gel adicionado de extrato alimentar foi lavado 10 vezes com $10 \mathrm{~mL}$ de PBS $0,05 \mathrm{M}, \mathrm{pH} 6,5$ e empacotado em coluna cromatográfica (15 x $130 \mathrm{~mm}$ ). A enterotoxina estafilocócica foi eluída com imidazol 0,05 M em PBS $0,05 \mathrm{M} \mathrm{pH} 6,5$, na velocidade de $3 \mathrm{~mL} / \mathrm{min}$, coletando-se frações de $1,0 \mathrm{~mL}$ (coletor LKB, Broma). O pico de eluição foi monitorado a $280 \mathrm{~nm}$, sendo que as frações correspondentes foram testadas perante a presença de enterotoxina estafilocócica pelo método de RPLA.

\subsection{AGLUTINAÇÃO DE LÁTEX-RPLA}

As enterotoxinas $A, B$, e $D$ foram detectadas diretamente nos alimentos pela aglutinação de látex (RPLA), utilizando-se o "kit" SET-RPLA (Denka Seiken Co. Ltd., Tokyo), conforme metodologia descrita por IGARASHI et al. (1986).

Nas cavidades de microplaca em $U$ foram colocados $25 \mu \mathrm{L}$ do extrato alimentar, seguido da adição de $25 \mu \mathrm{L}$ do látex sensibilizado com a correspondente anti-enterotoxina. Para os controles negativos foram utilizados $25 \mu \mathrm{L}$ de tampão fosfato $0,02 \mathrm{M}$, pH 7,2 ou "chantilly" sem contaminação, seguida de $25 \mu \mathrm{L}$ de látex sensibilizado. O controle positivo consistiu do mesmo tampão ou "chantilly" adicionado de concentração conhecida de EEA. A microplaca foi coberta com filme de PVC (Magipack) 
e agitada manualmente por 3 min, procedendo-se a leitura após 24 horas de incubação em temperatura ambiente (WIENEKE, 1991). A sensibilidade do látex e o nível de toxina nas amostras foram determinadas com base no ponto final das diluições seriadas e pela comparação da reação obtida com o controle positivo.

\section{RESULTADOS E DISCUSSÃO}

As Tabelas 1, 2 e 3 e a Figura 1 mostram a eficácia do método de eliminação de interferentes empregando-se a cromatografia de afinidade com íon $\mathrm{Cu}^{2+}$. Inicialmente foi utilizado "chantilly" artificialmente contaminado com EEA (Tabela 1 e 2) e, posteriormente, o mesmo método foi empregado na análise de diferentes produtos alimentícios naturalmente contaminados com estafilococos enterotoxigênicos (Tabela 3).

\section{TABELA 1 - DETECÇÃO DE EEA PELO RPLA NO EXTRATO DE "CHANTILLY" CONTAMINADO E NÃO-CONTAMINADO}

\begin{tabular}{cc}
\hline Fra I es & EEA(RPLA) \\
\hline Chantilly sem EEA & - \\
1 a 5 & - \\
6 a 13 & - \\
14 a 30 & \\
Chantilly contaminado & - \\
1 a 5 & + \\
6 a 13 & - \\
14 a 30 & \\
\hline
\end{tabular}

+Aglutinação; - Ausência de aglutinação; EEA = Enterotoxina Estafilocócica A; RPLA $=$ Reversed Passive Latex Agglutination .

O "chantilly" foi o alimento escolhido para o ensaio preliminar, já que contém os principais componentes químicos, como açúcares, lipídios e proteínas que normalmente causam reações falso-positivas no ensaio de RPLA (SOUZA-CUNHA, 1992). A primeira etapa de extração das toxinas baseou-se na acidificação em pH 4,5, no qual a maioria das proteínas solúveis alimentares precipita, o que não ocorre com as enterotoxinas estafilocócicas, cujo ponto isoelétrico situa-se em torno de 8,5 (FREED et al., 1982). O precipitado obtido em $\mathrm{pH} 4,5$ foi eliminado e, ocorrendo 
nova precipitação após o reajuste do $\mathrm{pH}$ para 7,2, incluiu-se mais uma etapa de centrifugação, usando assim apenas extratos límpidos na cromatografia.

A Tabela 1 mostra os resultados do RPLA realizado com os extratos de "chantilly" isentos e artificialmente contaminados com EEA, submetidos à cromatografia de afinidade com íon $\mathrm{Cu}^{2+}$. A ausência de EEA, observada em todas as 30 frações eluídas de extrato não-contaminado, indicou que o processo cromatográfico resultou na eliminação total de interferentes (Tabela 1).

Deve-se salientar que efetuando RPLA com extrato de "chantilly" nãocontaminado, sem etapa cromatográfica, ocorre reação falso-positiva até a diluição 1/8 (Tabela 2), o que inviabiliza a aplicação da RPLA para este grupo de produto alimentar. Para o controle de qualidade é necessário 0 emprego de metodologia capaz de detectar enterotoxina em amostra com diluição mínima, já que concentrações em nível de ng são capazes de desencadear intoxicação (EVENSON et al., 1988). Resultados similares foram obtidos por KAMOGAE (1994) que detectou reações falso-positivas no RPLA com extratos diluídos até 1:8 (creme), 1:64 (maionese) e 1:128 (queijo).

\section{TABELA 2 - REAÇÕES FALSO-POSITIVAS OBSERVADAS NO RPLA COM EXTRATOS DE "CHANTILLY" NÃO- CONTAMINADO COM EEA}

\begin{tabular}{lcccccccc}
\hline \multicolumn{1}{c}{ EXTRATO DE CHANTILLY (RPLA) } \\
\hline Dilui 응 & $1 / 2$ & $1 / 4$ & $1 / 8$ & $1 / 16$ & $1 / 32$ & $1 / 64$ & $1 / 128$ & $1 / 256$ \\
Rea aㅗ & + & + & + & - & - & - & - & - \\
\hline
\end{tabular}

+ Aglutinação; - Ausência de aglutinação.

RPLA = Reversed Passive Latex Agglutination.

A Tabela 1 mostra ainda os resultados obtidos com o extrato de "chantilly" previamente contaminado com 25 ng de EEA, submetidos à cromatografia de afinidade com íon $\mathrm{Cu}^{2+} \mathrm{e}$ análise das frações com RPLA. As frações coletadas e monitoradas a $280 \mathrm{~nm}$ apresentaram um pico único de eluição protéica, situado entre a $5^{\underline{a}}$ e a $9^{\underline{a}}$ fração. A eluição obtida está de acordo 
com DICKIE \& AKHTAR (1989) que observaram um pico de eluição de EEA entre a $19^{\underline{a}}$ e a $20^{\underline{a}}$ fração, procedendo o ensaio com $100 \mathrm{~mL}$ de extrato. Segundo tais autores, usando-se volume acima de $50 \mathrm{~mL}$, normalmente o pico de eluição ocorre entre a $12^{\underline{a}}$ e a 16aㅡ fração, já com volumes $\leq 50 \mathrm{~mL}$, o tempo de eluição torna-se reduzido e obtém-se pico entre a $5^{\underline{a}}$ e a $9^{\underline{a}}$ fração.

A Tabela 3 apresenta os resultados da análise por RPLA de 15 extratos alimentares contaminados com estafilococos enterotoxigênicos, avaliados microbiologicamente no LAPA/LACEN, Curitiba - PR. Submetendo-se todos os extratos ao método RPLA sem etapa cromatográfica, as enterotoxinas estafilocócicas foram detectadas em 13 alimentos. Os dois alimentos (lingüiça defumada e bolo recheado) que apresentaram reação negativa foram considerados grupo controle. A seguir, submetendo-se os mesmos extratos alimentares ao processo de limpeza via cromatografia de afinidade com íon $\mathrm{Cu}^{2+}, 11$ extratos apresentaram um único pico de eluição, com perfis semelhantes, conforme indicaram os exemplos apresentados pelas Figuras $1 \mathrm{~A}$ e 1B. Nestes extratos detectaram-se enterotoxinas estafilocócicas EEA (mortadela, bolo, carne moída e panqueca de carne), EEB (queijo frescal), EEA + EEB (queijo colonial, costela defumada e maionese), EEA + EED (queijo frescal e queijo prato) e EEA + EEB + EED (frango cru recheado). DICKIE \& AKHTAR (1989) relataram perfil cromatográfico semelhante ao observado neste trabalho, o que confirma a presença de enterotoxinas estafilocócicas. O tratamento do extrato alimentar com o gel de sepharose $6 \mathrm{~B}$ acoplado com íon $\mathrm{Cu}^{2+}$ permitiu a captação adequada de enterotoxinas estafilocócicas (Tabela 3, Figura 1). DICKIE \& AKHTAR (1989) obtiveram resultado positivo adicionando $1 \mathrm{ng}$ de EEA, EEB e EEC em $100 \mathrm{~mL}$ de extrato preparado com presunto, salame, salada de batatas, queijo tipo "Cheddar", pizza, bolo de frutas, ovo cozido e leite, o que indica a eficiência do método na recuperação das enterotoxinas estafilocócicas. MORENO (1997) recuperou até $0,225 \mathrm{ng}$ de EEA em extrato de "chantilly", previamente contaminado com 0,225 a $25 \mathrm{ng} / \mathrm{g}$ de EEA.

O pico de eluição coincidente com o padrão de enterotoxina eliminou a possibilidade da presença de outras exoproteínas comumente produzidas por estafilococos patogênicos, como a proteína $A$, com peso molecular de 42.000 Da (SJÖQUIST et al., 1972) ou TNAse com PM de $16.800 \mathrm{Da}$ (HIROOKA et al., 1992), já que as enterotoxinas apresentam peso molecular entre 28.000 e $35.000 \mathrm{Da}$ (HALPIN-DOHNALEK \& MARTH, 1989).

Os extratos dos três primeiros alimentos listados na Tabela 3 (mortadela, 


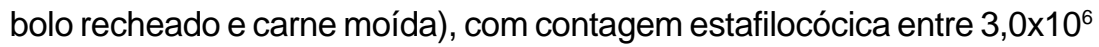
e 3,0 $\times 10^{7}$, positivas para EEA, apresentaram cromatogramas de frações eluídas com maior pico de leitura espectrofotométrica. O nível de

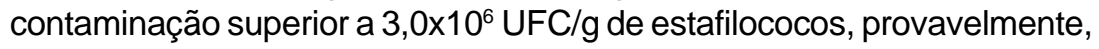
resultou em maior produção de toxina.

\section{TABELA 3 - CROMATOGRAFIA DE AFINIDADE COM ÍON $\mathrm{Cu}^{2+} \mathrm{E}$ ELIMINAÇÃO DE REAÇÕES FALSO-POSITIVAS NO MÉTODO RPLA ( $\mathrm{N}=15)$}

\begin{tabular}{|c|c|c|c|}
\hline \multirow[t]{2}{*}{ Alimentos } & \multirow{2}{*}{$\begin{array}{l}\text { Estafilococos } \\
\text { (UFC/g) })^{1}\end{array}$} & \multicolumn{2}{|c|}{ Enterotoxinas } \\
\hline & & RPLA & $\begin{array}{c}\text { Cromatografia afinidade } \\
\text { com on } \mathrm{Cu}^{2+}\end{array}$ \\
\hline Mortadela & $3,0 \times 10^{7}$ & A & $t^{2}$ \\
\hline Bolo recheado & $3,0 \times 10^{6}$ & A & + \\
\hline Carne mo da & $3,0 \times 10^{6}$ & A & + \\
\hline Panqueca de carne & $9,0 \times 10^{3}$ & A & + \\
\hline Queijo frescal & $7,0 \times 10^{3}$ & $B$ & + \\
\hline Queijo colonial & $3,0 \times 10^{5}$ & $A, B$ & + \\
\hline Costela defumada & $2,4 \times 10^{5}$ & $A, B$ & + \\
\hline Maionese & $9,0 \times 10^{4}$ & $A, B$ & + \\
\hline Queijo frescal & $3,0 \times 10^{5}$ & $A, D$ & + \\
\hline Queijo prato & $6,0 \times 10^{3}$ & $A, D$ & + \\
\hline Frango cru recheado & $7,7 \times 10^{4}$ & $A, B, D$ & + \\
\hline Bolo recheado & $<1,0 \times 10^{2}$ & a.i. ${ }^{3}$ & -4 \\
\hline Bolo recheado & $<1,0 \times 10^{2}$ & a.i. & - \\
\hline Ling i a defumada & $<1,0 \times 10^{2}$ & n.d. ${ }^{5}$ & - \\
\hline Bolo recheado & $<1,0 \times 10^{2}$ & n.d. & - \\
\hline
\end{tabular}

1 Dados fornecidos pelo LAPA-LACEN, Curitiba, PR.

2 Picos de eluição testados por RPLA e toxinas detectadas.

3 Aglutinação inespecífica.

4 Frações eluídas testadas por RPLA e reações inespecíficas eliminadas.

5 Enterotoxinas não-detectadas.

A cromatografia de afinidade com íon $\mathrm{Cu}^{2+}$ não diferenciou as enterotoxinas (Figura 1), já que nas amostras apresentando pico único no cromatograma foram detectados diferentes tipos sorológicos analisados via RPLA (Tabela 3). Todavia, a acuidade obtida é satisfatória visando a aplicação na etapa que precede a análise sorológica, pois as 10 lavagens sucessivas da coluna, contendo enterotoxina capturada pelo íon $\mathrm{Cu}^{2+}$, eliminariam eficientemente os interferentes. Outra opção objetivando aumentar a especificidade seria a imobilização de anticorpos na coluna de imunoafinidade, como descreve NEDELKOV et al. (2000). 
FIGURA 1 - CROMATOGRAMAS DEELUIÇÃOUTILIZANDO COLUNADE AFINIDADE COM ÍON $\mathrm{CU}^{2+}$, EM ALIMENTOS NATURALMENTE CONTAMINADOS COMENTEROTOXINAS ESTAFILOCÓCICAS
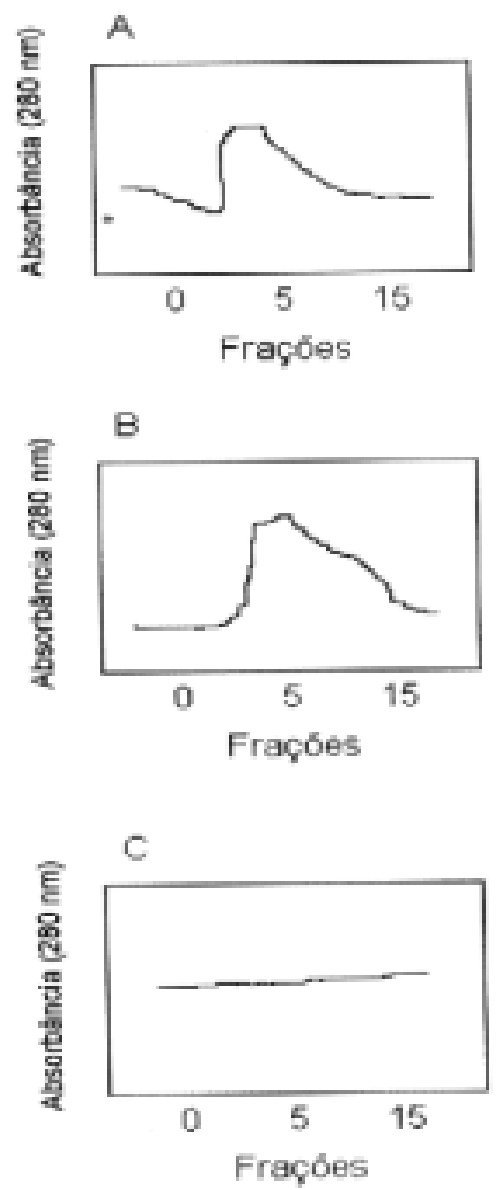

$A=$ queijo frescal com $E B ; B=$ panqueca de carne com $E E A$ e $E E B ; C$ = bolo recheado sem enterotoxina. 
A eficácia da coluna de afinidade na eliminação de interferentes foi demonstrada na eluição de enterotoxinas em dois extratos de bolos recheados que anteriormente apresentaram reações falso-positivas via RPLA (Tabela 3). A Figura 1C evidenciou que o cromatograma de bolo recheado negativo para enterotoxina não acusou nenhum pico de eluição. Estes resultados confirmam a adequação da metodologia e são condizentes com os dados anteriores obtidos por SOUZA-CUNHA (1992) que notou maior interferência causada por componentes glicídicos. $O$ risco da interferência de matrizes alimentares não-glicídicas não deve ser descartado, já que KAMOGAE (1994) detectou falsa-positividade em RPLA usando extrato de queijo diluído a 1:128. Provavelmente, a diferença na composição, dentro de mesmo grupo alimentar, poderia causar diversidade na reação de aglutinação. A cromatografia com íon $\mathrm{Cu}^{2+}$ também foi eficiente para eliminar reações inespecíficas em amostras de frutos do mar testadas com o "kit" TECRA (PARK et al., 1993). Por outro lado, estes fatos indicam que a inclusão da etapa com cromatografia de afinidade com íon $\mathrm{Cu}^{2+}$ poderia viabilizar a utilização de anticorpos policlonais na detecção de enterotoxina via RPLA, reduzindo o custo da produção de reagentes imunológicos.

\section{CONCLUSÃO}

O trabalho atingiu o objetivo solucionando em parte os problemas com os interferentes alimentares, principalmente os glicosídicos, na detecção de enterotoxinas estafilocócicas por RPLA, utilizando-se a cromatografia de afinidade com íon $\mathrm{Cu}^{2+}$. Entretanto, a complexidade do método e o elevado custo da sepharose limitam o uso na rotina laboratorial, devendo-se realizar mais estudos no sentido de viabilizar sua aplicação com maior simplicidade e reduzir o tempo de eliminação de interferentes.

\section{Abstract \\ CU ${ }^{2+}$ AFFINITY CHROMATOGRAPHY: ELIMINATION OF FALSE-POSITIVE IN THE DETECTION OF STAPHYLOCOCCAL ENTEROTOXIN}

The application of $\mathrm{Cu}^{2+}$ chelate Sepharose affinity chromatography was evaluated to reduce the interference of food constituents in the detection of staphylococcal enterotoxin with reversed passive latex agglutination immunoassay (RPLA). The preliminary assay using chantilly contaminated with 25 nanograms of staphylococcal enterotoxin A (SEA) indicated that $\mathrm{Cu}^{2+}$ ion affinity chromatography eliminated the food matrix constituents responsible for false-positive reaction of RPLA. The efficiency of this clean-up procedure was tested in 15 food extracts (from outbreaks and/or with high staphylococcal count), 
comprising various types of food commonly consumed in Brazil. Eleven food extracts showed only one elution peak with similar profile and the fractions assayed by RPLA demonstrated SEA (4 food), SEB (1), SEA + SEB (3), SEA + SED (2) e SEA + SEB + SED (1). The problems of nonspecific reactions with the RPLA kit in 2 cake extracts were eliminated, indicating that the adoption of this operation avoids the false-positive reaction.

KEY WORDS: CHROMATOGRAPHY; ENTEROTOXIN; CU ${ }^{2+}$ ION; FOOD CONTAMINATION.

\section{REFERÊNCIAS}

1 CARMO, L.S.; VIEIRA, A.C.; PARENTE-REIS, J.D.; BERGDOLL, M.S. Staphylococcus aureus and Salmonella enteritidis in food poisoning. Revista de Microbiologia, v. 27, n. 2, p. 122-125, 1996.

2 CHANG, T.C.; HUANG, S.H. An enzyme-linked immunosorbent assay for the rapid detection of Staphylococcus aureus in processed foods. Journal of Food Protection, v. 57, n.3, p. 184-189, 1994.

3 DICKIE, N.; AKHTAR, M. Concentration of staphylococcal enterotoxin from food extract using cooper chelate sepharose. Journal of Food Protection, v. 52, n. 12, p. 903-905, 1989.

4 EVENSON, M.L.; HINDS, M.W.; BERNSTEIN, R.S.; BERGDOLL, M.S. Estimation of human dose of staphylococcal enterotoxin A from a large outbreak of staphylococcal food poisoning involving chocolate milk. International Journal of Food Microbiology, v. 7, p. 311316, 1988.

5 FREED, R.C.; EVENSON, M.L.; REISER, R.F.; BERGDOLL, M.S. Enzyme linked immunosobent assay for detection of staphylococcal enterotoxins in foods. Applied \& Environmental Microbiology, v. 44, n.6, p. 1349-1355, 1982.

6 HALPIN-DOHNALEK, M. I.; MARTH, E. H. Staphylococcus aureus: production of extracellular compounds and behavior in foods, a review. Journal of Food Protection, v. 52, n. 4, p. 267-268, 1989.

7 HIROOKA, Y. H.; VICENTE, E.; YOSHIMOTO, Y. et al. A rapid and low cost adaptation of staphylococcal TNAse detection in milk. Revista de Microbiologia, v. 23, n. 4, p. 243-249, 1992.

8 IGARASHI, H. et al. Latex agglutination test for staphylococcal toxic schock syndrome toxin1. Journal of Clinical Microbiology, v. 23, n.3, p. 509-512, 1986. 
9 KAMOGAE, M. Produção e purificação de enterotoxina estafilocócica A e sua aplicação em testes imunológicos rápidos em alimentos. Londrina, 1994. 78 p. Dissertação (Mestrado) - Centro de Ciências Agrárias, Departamento de Tecnologia de Alimentos e Medicamentos, Universidade Estadual de Londrina.

10 KAWANO, Y.; ITO, Y.; YAMAKAWA, Y.; YAMASHIRO, T.; HORII, T.; HASEGAWA, T.; OHTA, M. Rapid isolation and identification of staphylococcal exoproteins by reverse phase capillary high performance liquid chromatography-electrospray ionization mass epectrometry. FEMS Microbiology Letters, v. 189, n. 1, p. 103$108,2000$.

11 LÖNNERDAL, B.; KEEN, C.L. Metal chelate affinity chromatografy of proteins. Journal of Applied Biochemistry, v. 4, p. 203-208, 1982.

12 MORENO, C. M. Produção de enterotoxina estafilocócica A para testes imunológicos rápidos em alimentos e redução de interferentes na aglutinação de látex-RPLA. Londrina, 1997. 95 p. Dissertação (Mestrado) - Centro de Ciências Agrárias, Universidade Estadual de Londrina.

13 MORISSETE, C.; GOULET, J.; LAMOUREAUX, G. Rapid and sensitive sandwich enzyme-linked immunosorbent assay for detection of staphylococcal enterotoxin B in cheese. Applied Environmental Microbiology, v. 57, n. 3, p. 836-842, 1991.

14 NEDELKOV, D.; RASOOLY, A.; NELSON, R.W. Multitoxin biosensor-mass spectrometry analysis: a new approach for rapid, real-time, sensitive analysis of staphylococcal toxins in food. International Journal of Food Microbiology, v. 60, n. 1, p. 1-13, 2000.

15 OLIVEIRA, T.C.R.M. Produção de reagentes imunológicos para a detecção direta de enterotoxina estafilocócica em alimentos. Londrina, 1994. 97 p. Tese (Doutorado) - Centro de Ciências Agrárias, Departamento de Tecnologia de Alimentos e Medicamentos, Universidade Estadual de Londrina.

16 PARK, C.E.; AKHTAR, M.; RAYMAN, M.K.. Simple solutions to false positive staphylococcal enterotoxin assays with seafood tested with an enzyme linked immunosorbent assay kit (TECRA). Applied \& Environmental Microbiology, v. 59, n. 7, p. 2210-2213, 1993. 
17 PARK, C. E.; SZABO, R. Evaluation of the reversed passive latex agglutination (RPLA) test kits for detection of staphylococcal enterotoxins $A, B, C$ and $D$ in foods. Canadian Journal of Microbiology, v. 32, p. 723-727, 1986.

18 PARK, C.E.; WARBURTON, D. A collaborative study on the detection of staphylococcal enterotoxins in food with an enzyme immunoassay kit (TECTRA). Journal of Food Protection, v. 59, n. 4, p. 390-397, 1996.

19 PORATH, J. et al. Metal chelate affinity chromatography, a new approach to protein fraction. Nature, v. 258, n.12, p. 598-599, 1975.

20 RASOOLY, A.; ITO, Y. Toroidal coil countercurrent chromatography and analysis of staphylococcal enterotoxin $A$ in milk. Journal of Liquid Chromatography \& Related Technologies, v. 22, n. 9, p. 1285-1293, 1999.

21 RASOOLY, A.; ITO, Y. Toroidal coil countercurrent chromatography separation of Staphylococcus aureus enterotoxin A in food. Journal of Liquid Chromatography \& Related Technologies, v. 21, n. 12, p. 93-102, 1998.

22 ROSE, S.A.; BANKES, P.; STRINGER, M.F. Detection of staphylococcal enterotoxins in dairy products by the reversed passive latex agglutination (SET-RPLA) kit. International Journal of Food Microbiology, v. 8, p. 65-72, 1989.

23 SJÖQUIST, J.; MOVITZ, J.; JOHANSSON, I.B. et al. Localization of protein $A$ in the bacteria. European Journal of Biochemistry, $v$. 30, n. 1, p. 190-194, 1972.

24 SOUZA-CUNHA, M.L.R. Estafilococos enterotoxigênicos: efeito de cultura mista em leite, extrato de soja e parâmetros causadores de injúria celular. Londrina, 1992. 86 p. Dissertação (Mestrado) Centro de Ciências Agrárias, Departamento de Tecnologia de Alimentos e Medicamentos, Universidade Estadual de Londrina.

25 WIENEKE, A. A. Comparison of four kits for the detection of staphylococcal enterotoxin in foods from outbreaks of food poisoning. International Journal of Food Microbiology, v. 14, p. 305-312, 1991.

26 WIENEKE, A. A.; GILBERT, R.J. Comparison of four methods for the detection of staphylococcal enterotoxin in foods from outbreaks 
of food poisoning. International Journal of Food Microbiology, v. 4 , p. 135-143, 1987.

\section{AGRADECIMENTOS}

Os autores agradecem ao Laboratório de Apoio Animal (LAPA) - Ministério de Agricultura do Abastecimento e da Reforma Agrária (MAARA) e Laboratório Central do Estado do Paraná (LACEN) - Secretaria de Estado da Saúde - Instituto de Epidemiologia do Paraná (SESA-ISEP) pelo fornecimento de amostras de alimentos. À CAPES pela Bolsa de Mestrado para Claudia V. Nervino e Claudia M. Rosa; ao CNPq pela Bolsa de Doutorado a Márcia Kamogae e Bolsa de Produtividade a Elisa Y. Hirooka. Ao Edson L. Z. Figueira, pelo auxílio na confecção dos cromatogramas. Em especial, ao Dr. Merlin S. Bergdoll (in memorian), pelo contínuo estímulo à pesquisa com enterotoxinas estafilocócicas. 